\title{
Catalytic Alkaline Oxidation of Lignin and its Model Compounds: a Pathway to Aromatic Biochemicals
}

\author{
Ali Azarpira • John Ralph • Fachuang Lu
}

Published online: 28 June 2013

(C) The Author(s) 2013. This article is published with open access at Springerlink.com

\begin{abstract}
Catalytic oxidation via the application of molecular oxygen and copper complexes is a useful pathway toward valuable low molecular mass compounds from in situ or waste stream lignins. In this study, two dimeric $\beta$-ether model compounds, one $\beta$-ether oligomer, and a milled wood lignin sample from Loblolly pine were catalytically oxidized. Yields and stability of the aromatic aldehyde and acid products were measured. Nuclear magnetic resonance spectroscopy and gel permeation chromatography were used to monitor structure/composition and molecular mass changes of the lignin before and after catalytic oxidation to study the degree of depolymerization and structure of the residual lignin. Oxidized units appear to be derived from $\beta$-aryl ether, phenylcoumaran, and biphenyl ether components. To date, this method breaks down the lignin polymeric structure reasonably effectively, producing low molecular mass products; this work also highlights some of the issues that need to be overcome to optimize this approach.
\end{abstract}

Keywords Pine lignin $\cdot 2 \mathrm{D}$ NMR $\cdot$ Lignin $\beta$-ether units · Copper-phenanthroline catalyst

Electronic supplementary material The online version of this article (doi:10.1007/s12155-013-9348-x) contains supplementary material, which is available to authorized users.

A. Azarpira · J. Ralph · F. Lu ( $\bowtie)$

Great Lakes Bioenergy Research Center,

Wisconsin Energy Institute, University of Wisconsin,

1552 University Avenue, Madison, WI 53726, USA

e-mail: fachuanglu@wisc.edu

J. Ralph • F. Lu

Department of Biochemistry, University of Wisconsin,

Madison, WI, USA

\section{Introduction}

Refinery operations on fossil fuels are the main source of chemicals used in society today. Uncertain availability, price surges, and environmental concerns regarding the utilization and refinery of fossil sources have created a demand for alternative ways to obtain chemicals based on renewables [1].

The pulp and paper industry produces millions of tons of lignins annually; however, all but a small percentage of the lignin is burned as fuel to greatly aid the energetic balance of the process and, particularly in the case of kraft pulping, to recover the inorganic pulping chemicals [2]. Particularly with the emergence of lignocellulosic biomass to biofuel initiatives, significant streams of lignin may become available at relatively low cost, offering potential value to the chemical industry for production of a range of chemicals - lignin is one of few large natural resources for aromatics [3-5]. Lignins are phenolic high molecular mass biopolymers biosynthesized from chemical oxidative coupling of, mainly, monolignols $\mathbf{M}$, i.e., p-coumaryl (MH), coniferyl (MG), and sinapyl (Ms) alcohols (Fig. 1a). These monolignols produce, respectively, $p$-hydroxyphenyl $(\mathbf{P H})$, guaiacyl $\left(\mathbf{P G}_{\mathbf{H}}\right)$, and syringyl $(\mathbf{P s})$ units in the polymer $\mathbf{P}$ (Fig. 1b) [6-8]. Monomers couple with each other but, more importantly, endwise cross-couple in a combinatorial fashion with growing oligomers to produce the complex, mildly branched, lignin polymers. Inter-unit linkage types are defined by the way a monomer or a preformed oligomer (cross-)couples with another phenolic unit; the common ones involve $\beta-\mathrm{O}-4-, \beta-5-, \beta-\beta-, 5-5$ - (usually as dibenzodioxocins), and 5-O-4-coupling (Fig. 1c) [9].

Conversion of lignins to a small array of simple compounds is a challenge due to its complexity. Many degradation methods, such as pyrolysis, simply give too vast an array of compounds, although such mixtures can be useful in other ways. Three major methods can give rise to relatively decent 
a) Monomers

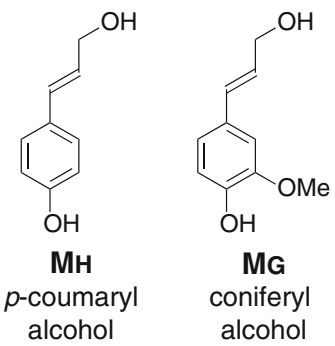

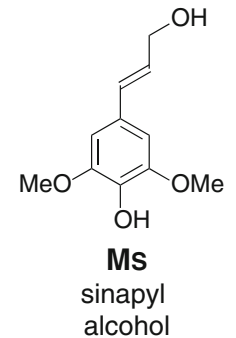

b) Generic Lignin Unit

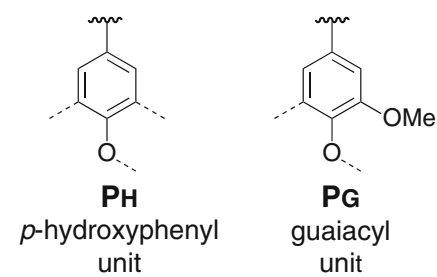

c) Major structural units in the polymer
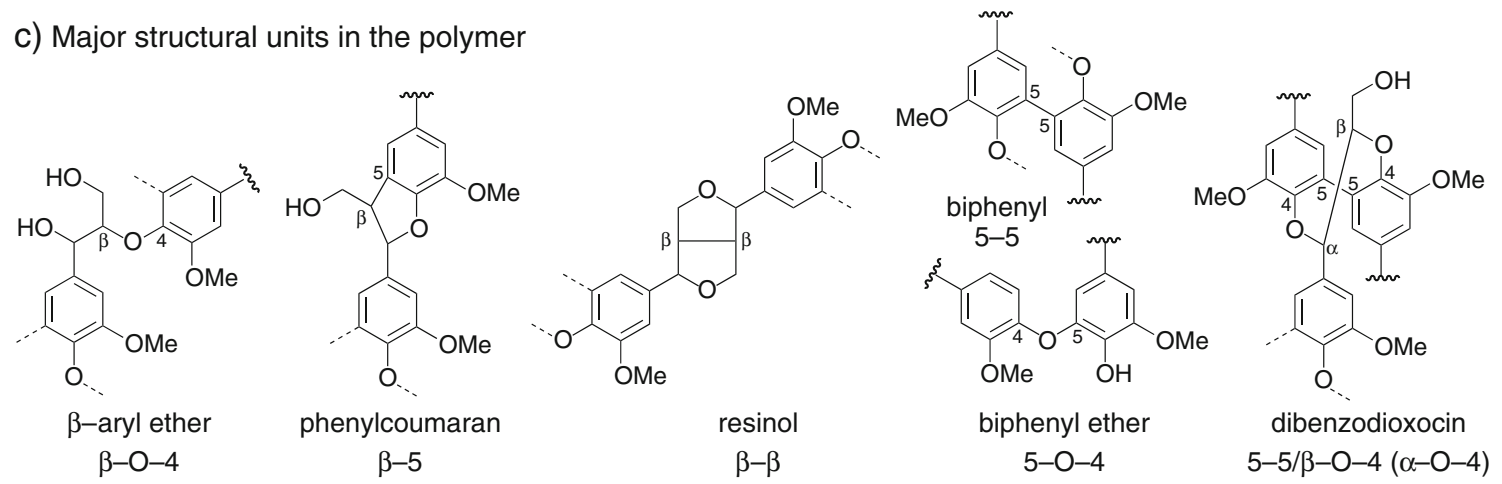

Fig. 1 a Primary lignin monomers $\mathbf{M}$, the monolignols. b Lignin polymer $\mathbf{P}$ units are denoted based on the methoxyl substitution on the aromatic ring as generic PH, PG, and Ps units. c Major structural units in the lignin. [Modified from [8]

yields of a small array of simple compounds. These include: (1) oxidation to the simple aldehydes or acids, primarily vanillin and syringaldehyde or vanillic and syringic acid; (2) acidolytic or reductive cleavage methods (that have mostly been used in analytical methods such as acidolysis, thioacidolysis, and the DFRC method) that give rise to various arylpropanoid monomers [10]; and (3) hydrogenolysis to produce arylpropanes or arylpropanols [11].

When considering oxidative degradation methods, molecular oxygen is an attractive oxidant because it is inexpensive, abundant, nontoxic, and environmentally friendly [12]. Catalytic oxidation for obtaining value-added products from lignin $[11,13,14]$ as well as for delignification of pulp [15-17] have been the subject of many studies.

Many metalloenzymes that catalyze aerobic oxidation reactions have copper in their active sites [18]. Application of copper in catalytic aerobic oxidation reactions is well known [19]. Homogeneous copper-phenanthroline complexes have been used in catalytic oxidation reactions and wood delignification [20,21]. Addition of copper sulfate to phenanthroline under alkaline aqueous conditions leads to the formation of various complexes depending on the $\mathrm{pH}$ and ligand-to-copper molar ratio. During oxidation of a substrate, $\mathrm{Cu}$ (II) is reduced to $\mathrm{Cu}(\mathrm{I})$ which is oxidized back to $\mathrm{Cu}$ (II) species in the presence of molecular oxygen [22]. Meanwhile, the presence of several other entities makes the whole process more complicated. Electrophilic species (e.g., hydroxyl radical and oxygen biradical) and nucleophilic species (e.g., hydroperoxide anions and superoxide anion radicals) are proposed to be present. These short-lived active species arise from stepwise reduction of molecular oxygen in the presence (or absence) of metal ions [23-26]. Whereas copper complexes activate molecular oxygen for a variety of reactions, the complex reaction mixture makes it hard to define possible optimum conditions for either delignification or production of fine chemicals.

Lignin oxidation products are predominantly aromatic aldehydes or acids depending on the reaction conditions. Alkaline oxidation of softwood lignin produces vanillin and vanillic acid, whereas syringaldehyde and syringic acid are also obtained from hardwood/dicot or monocot lignins $[26,27]$. Among lignin inter-unit linkage types, the $\beta-\mathrm{O}-4$ unit ( $\beta$-ether) is the main focus for industrial processes because of its predominance and its relatively easy cleavability. Considering the complexity of lignin polymer, model compounds with linkages and functional groups commonly found in native polymer are often valuable to home in on reactions and conditions that hold promise. The value of model compound investigations is that, whereas it is not a given that a condition that works well on a model compound will necessarily also work well on the lignin polymer, it is certainly true that a method that does not work well on a model has no chance of being useful for the polymer.

This paper describes the alkaline oxidation, using molecular oxygen, of $\beta$-ether dimer and oligomer model compounds as well as a softwood lignin (Loblolly pine milled wood lignin) using a copper-phenanthroline complex as catalyst. Structural changes to the lignin help to elucidate 
yield bottlenecks in attempting to apply oxidative methods to lignins industrially.

\section{Material and Methods}

\section{General}

1,10-Phenanthroline was bought from Acronis and used as supplied. Copper(II) sulfate pentahydrate, sodium hydroxide, and other chemicals were purchased from SigmaAldrich. LC-MS grade solvents for analysis were from Fisher. A cylinder of ultra high purity oxygen was purchased from Airgas.

\section{Analysis}

LC-MS analysis was conducted on a Shimadzu LCMS-2020 (Shimadzu, Kyoto, Japan) equipped with SPD-M20A photodiode array detector using following conditions: column: Kinetex C18, $2.6 \mu \mathrm{m}$, PFP, 100A, 150×4.6 mm, USA; column oven temperature, $40^{\circ} \mathrm{C}$; photodiode array (PDA) response at $254 \mathrm{~nm}$; mobile phase: solvent B (methanol) from 10 to $90 \%$ in $15 \mathrm{~min}$, held at $90 \%$ for $11 \mathrm{~min}$, from 90 to $10 \%$ in $1 \mathrm{~min}$, held at $10 \%$ to the end of the run (40 min) and solvent A: aqueous $0.1 \%$ formic acid; and flow rate, $0.7 \mathrm{~mL} \mathrm{~min}^{-1}$.

Gel permeation chromatography (GPC) was performed on a Shimadzu LC-20A LC system (Shimadzu, Kyoto, Japan) equipped with a PDA detector (SPD-M20A; Shimadzu) using following conditions: column: TSK gel $\alpha-\mathrm{M}+\alpha-2500$ (Tosoh, Tokyo, Japan); eluent, $0.1 \mathrm{M} \mathrm{LiBr}$ in dimethylformamide (DMF); flow rate, $0.5 \mathrm{~mL} \mathrm{~min}{ }^{-1}$; column oven temperature, $40{ }^{\circ} \mathrm{C}$; and sample detection: PDA response at $280 \mathrm{~nm}$. Molecular weight calibration was made via polystyrene standards (molecular weight (MW) from 266 up to 3,840,000; Tosoh, Tokyo, Japan). For data acquisition and computation, we used LCsolution version 1.25 software (Shimadzu).

Nuclear magnetic resonance (NMR) spectra of samples in DMSO- $\mathrm{d}_{6} /$ pyridine- $\mathrm{d}_{5}(4: 1, v / v)$ were acquired by using a Bruker Biospin (Billerica, MA, USA) AVANCE 500 $(500 \mathrm{MHz})$ spectrometer fitted with a cryogenically cooled $5 \mathrm{~mm}$ TCI gradient probe with inverse geometry (proton coils closest to the sample) and spectral processing used Bruker's Topspin 3.1 (Mac) software. The central DMSO solvent peaks were used as internal reference $\left(\delta_{\mathrm{H}} / \delta_{\mathrm{C}}=2.50 / 39.51\right)$.

\section{Alkaline Oxidative Reaction Procedure}

Two pressure vessels (10 and $30 \mathrm{~mL}$ ) each connected with a multi-port lid (stainless steel grade 316) from HEL Inc., USA were used to perform the oxidation reactions. The internal surface of each vessel was found to interfere with the oxidative condition of the reactions so we cut and inserted glass test tubes into each vessel to make sure the interior of our system was not involved in the oxidation reactions. Based on previous publications $[21,22]$ and our preliminary experiments, we ran the reactions at $80^{\circ} \mathrm{C}$. A 0.05 molar equivalent of catalyst per mole of compounds $\mathbf{1}$ and $\mathbf{2}$ and per mole of monomer units (for compounds 3 and 4 ) was added. Catalyst solution was made by stirring a 2:1 mixture of 1,10-phenanthroline and copper(II) sulfate pentahydrate in $0.5 \mathrm{M} \mathrm{NaOH}$ solution at room temperature. To the vessel, $3 \mathrm{mg}$ internal standard (3,5-dimethoxy benzoic acid) was added to a stirred solution of $15 \mathrm{mg}$ of test compound in $200 \mu \mathrm{L}$ methanol (co-solvent). The requisite amount of catalyst solution was added and diluted with $0.5 \mathrm{M}$ $\mathrm{NaOH}$ solution to the total reaction volume of $10 \mathrm{~mL}$. Internal standard (IS) was added to reaction mixture to correct any volume changes that could result from opening and closing the vessel several times to sample the reaction mixture for analysis. We observed a minute decomposition of IS at longer reaction times with higher oxygen pressure which was considered in our yield calculations. The vessel was then sealed and connected safely to the oxygen cylinder using proper Teflon tubing and stainless steel joints to maintain 0.27 or $1.24 \mathrm{MPa}$ $\mathrm{O}_{2}$ constant pressure inside the vessel. UV standard curves (at $254 \mathrm{~nm}$ ) were made using authentic synthetic compounds (for dimers) and commercial compounds (for monomers) and were used for determining the yields of the reactions for compounds $\mathbf{1}$ and $\mathbf{2}$. Yields of the reactions of oligomer (compound $\mathbf{3}$ ) and pine milled wood lignin (MWL) (compound 4) were determined similarly (by using molecular weight of the internal unit ( $\beta$-ether unit, MW=196) to calculate the number of the moles of the corresponding starting materials).

\section{Preparation of Model Compounds}

Dimer and oligomer model compounds were synthesized as previously reported with minor modifications $[28,29]$. The sample of MWL from Loblolly pine (Pinus taeda) was prepared as described [30].

Monitoring Alkaline Oxidative Degradation of Pine Lignin

Sample preparation for HPLC monitoring was conducted as follows. A $3-\mu \mathrm{L}$ aliquot of the oxidation reaction mixture solution from the oxidation of pine MWL 4 was subjected periodically to LC-MS analysis without further treatment or filtration. Sample preparation for GPC monitoring was conducted as follows: $\mathrm{HCl}(5 \mathrm{~N}, 20 \mu \mathrm{L})$ was added to $200 \mu \mathrm{L}$ icecooled (periodically collected) samples of the oxidation reaction mixture solution to terminate the reaction. To this, $780 \mu \mathrm{L}$ DMF containing $0.1 \mathrm{M} \mathrm{LiBr}$ was added and the obtained final solution was directly subjected to GPC analysis. Sample preparation for NMR monitoring was conducted as follows: individual reactions (each comprising $15 \mathrm{mg}$ of lignin) were run separately under the same conditions for 1, 3, and $10 \mathrm{~h}$. Each 
time, $0.5 \mathrm{~mL}$ of $5 \mathrm{~N} \mathrm{HCl}$ was added to stirred solution of the ice-cooled reaction mixture to acidify and precipitate the lignin. Resultant precipitates were collected by filtration through a nylon membrane (pore size, $0.45 \mu \mathrm{m}$ ), washed with $0.01 \mathrm{M}$ aqueous $\mathrm{HCl}(20 \mathrm{~mL})$, and lyophilized to yield $10 \mathrm{mg}$ (66.6 wt\%), $7.8 \mathrm{mg}(52 \mathrm{wt} \%)$, and $2.9 \mathrm{mg}(19.3 \mathrm{wt} \%$ ) solid material, respectively. The obtained material was dissolved in DMSO- $\mathrm{d}_{6} /$ pyridine- $_{5}(4: 1, v / v)$ and subjected to NMR analyses [31, 32].

\section{Results and Discussion}

Results from the catalytic alkaline oxidation of the common $\beta$-ether model dimer guaiacylglycerol- $\beta$-guaiacyl ether [1-(4hydroxy-3-methoxyphenyl)-2-(2-methoxyphenoxy)-propane1,3-diol] 1 at $0.27 \mathrm{MPa}$ (40 psi) $\mathrm{O}_{2}$ pressure are presented in Figs. 2 and $3 \mathrm{a}$ and Table $\mathrm{S} 1$ (see supporting information). As expected, cleaving the $\beta$-ether bond yielded different ratios of oxidized monomeric products from the lignin-representative ring A, i.e., 4-hydroxy-3-methoxybenzoic acid (vanillic acid) 1a and 4-hydroxy-3-methoxybenzaldehyde (vanillin) 1b, along with 2-methoxyphenol (guaiacol) 1c from the less

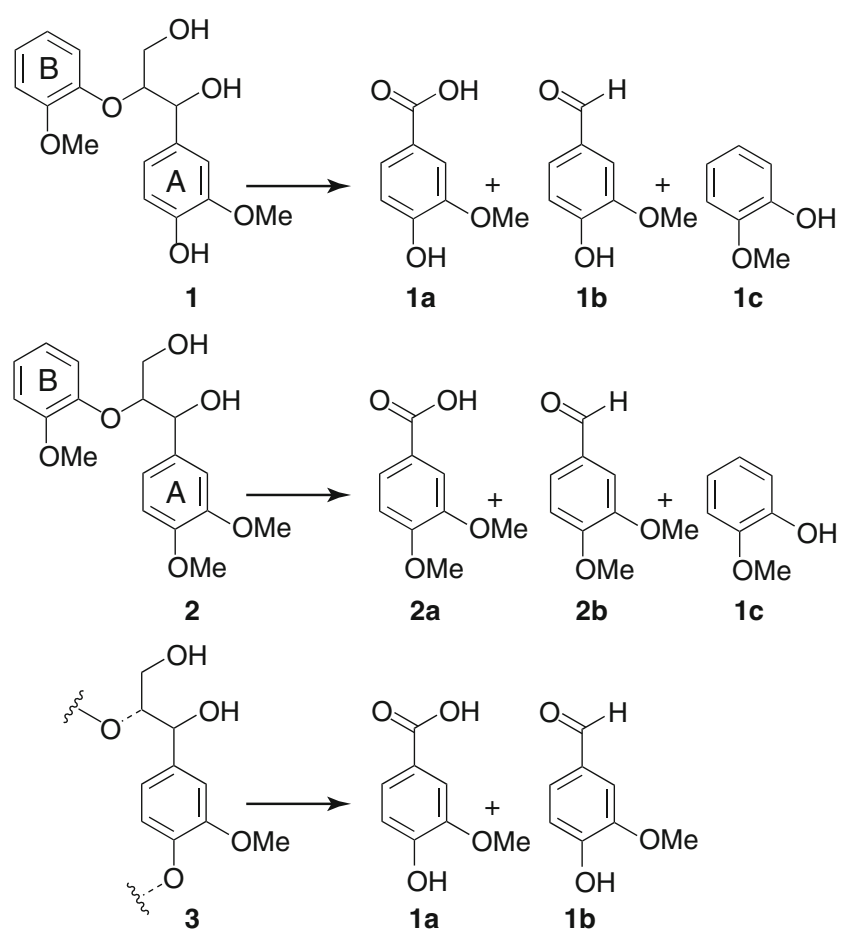

Fig. $2 \mathrm{Cu}$-catalyzed oxidation reaction scheme for model compounds $1-$ 3. 1: guaiacylglycerol- $\beta$-guaiacyl ether [1-(4-hydroxy-3-methoxyphenyl)-2-(2-methoxyphenoxy)propane-1,3-diol], 2: veratrylglycerol- $\beta$ guaiacyl ether [1-(3,4-dimethoxyphenyl)-2-(2-methoxyphenoxy)propane-1,3-diol], 3: $\beta$-O-4- ( $\beta$-ether) oligomer, 1a: 4-hydroxy-3-methoxybenzoic acid (vanillic acid), 1b: 4-hydroxy-3-methoxybenzaldehyde (vanillin), 1c: 2-methoxyphenol (guaiacol) 2a: 3,4-dimethoxybenzoic acid (veratric acid), 2b: 3,4-dimethoxybenzaldehyde (veratraldehyde) representative ring B (see Fig. 2). Vanillin $\mathbf{1 b}$ was the major identified product from throughout most of the reactions; as the reaction proceeded, the fraction of the starting model and other products declined. This decrease in the yields of all identifiable monomeric products during the reaction suggested that the products were not stable under these conditions. Although the instability of guaiacol 1c was expected, we were expecting that any decrease in vanillin $\mathbf{1 b}$ would be accompanied by a comparable increase in its oxidized counterpart, vanillic acid 1a, but that was not the case. Instead, both acid and aldehyde yields decreased over time. HPLC chromatograms of products from this reaction (Fig. 4a) at different times showed that the (observable fraction of the) reaction mixture was rather simple. The presence of a sharp unresolved peak at low retention time $(\sim 2.4 \mathrm{~min})$ in the chromatogram from the 20-h reaction suggested the presence of very small hydrophilic compounds in the reaction mixture that were produced as the reaction proceeded; we were unable to resolve and identify them.

The observed initial increase and later decrease in the yields of products $(\mathbf{1 a}, \mathbf{1 b}$, and $\mathbf{1 c})$ that we observed in this reaction suggested the occurrence of continual post-(degradation) pathways that could include gasification of compounds-we did not observe complicated HPLC chromatograms for reactions run at $0.27 \mathrm{MPa}(40 \mathrm{psi}) \mathrm{O}_{2}$.

In order to measure the effect of the catalyst, the same reaction without catalyst was conducted (Figs. 2 and S1a and Table S2). At the end of the reaction, $25 \%$ of compound 1 remained, whereas the yields for vanillin $\mathbf{1 b}$ and guaiacol $\mathbf{1 c}$ increased continuously; vanillic acid 1a was not detected up to $20 \mathrm{~h}$. This suggested that the oxidation condition without catalyst was not able to produce acid 1a, compound $\mathbf{1}$ remained, and the yields of $\mathbf{1 b}$ and $\mathbf{1 c}$ were lower compared to the catalytic oxidation reaction.

The effect of $\mathrm{O}_{2}$ pressure was also determined. Compound 1 was catalytically oxidized at elevated $\mathrm{O}_{2}$ pressure of $1.24 \mathrm{MPa}$ (180 psi) (Figs. 2 and S1b and Table S3). Residual compound 1 was not detected after $3 \mathrm{~h}$. Compared to the same time period for reaction of compound $\mathbf{1}$ at $0.27 \mathrm{MPa}$ (40 psi) $\mathrm{O}_{2}$, the yields of individual products were lower. The HPLC chromatograms for reactions at $1.24 \mathrm{MPa}$ (180 psi) (not shown) were very complicated compared with the same reaction at $0.27 \mathrm{MPa}$ (40 psi) (Fig. 4a), suggesting the presence of many new products and side reactions as a consequence of increased $\mathrm{O}_{2}$ pressure.

It was important to determine to what extent the free phenol was responsible for the limited yields of the primary oxidation products (from ring A). Results of catalytic alkaline oxidation of the phenol-methylated $\beta$-ether dimeric model veratrylglycerol- $\beta$-guaiacyl ether [1-(3,4-dimethoxyphenyl)-2-(2-methoxyphenoxy)-propane-1,3-diol] 2 at $0.27 \mathrm{MPa}$ (40 psi) $\mathrm{O}_{2}$ pressure are shown at Figs. 2 and S1c and Table S4. A continual increase in yields of 3,4- 


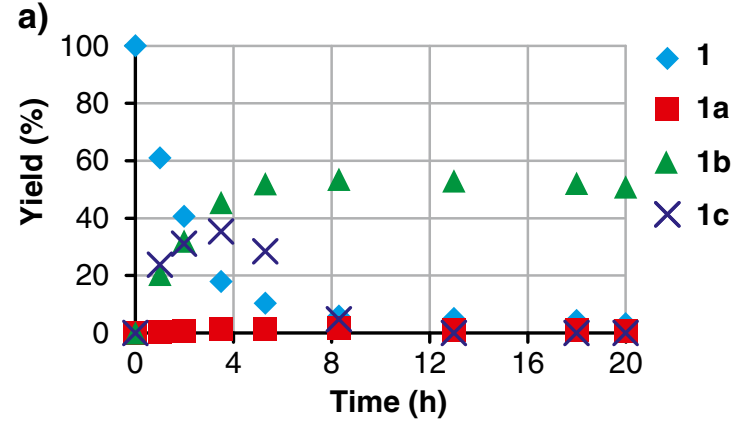

c)

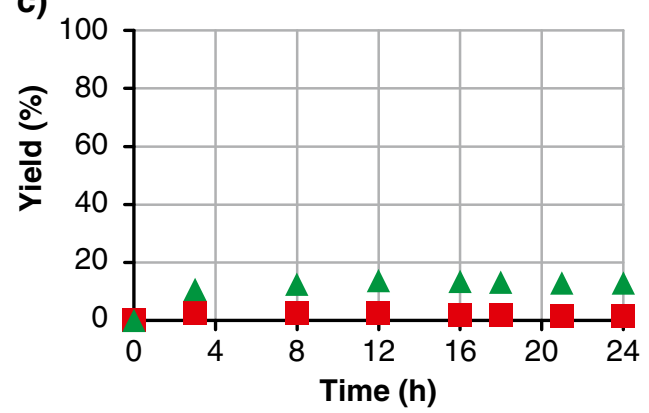

Fig. 3 Yield data from catalytic oxidation of (a) compound 1 at $0.27 \mathrm{MPa}$ (40 psi) $\mathrm{O}_{2}$ (data from Table $\mathrm{S} 1$ ), (b) compound 2 at $1.24 \mathrm{MPa}$ (180 psi) $\mathrm{O}_{2}$ (data from Table S5), (c) compound 3 ( $\beta$-ether

dimethoxybenzoic acid (veratric acid) 2a and 3,4-dimethoxybenzaldehyde (veratraldehyde) $\mathbf{2 b}$ was observed over $24 \mathrm{~h}$ while $25 \%$ of compound 2 remained at the end. Guaiacol 1c content of the reaction mixture increased and later dropped to $0 \%$ at $24 \mathrm{~h}$.

To analyze the effect of higher $\mathrm{O}_{2}$ pressure, the reaction was repeated at 1.24 $\mathrm{MPa}(180 \mathrm{psi}) \mathrm{O}_{2}$ pressure (Figs. 2, 3b,

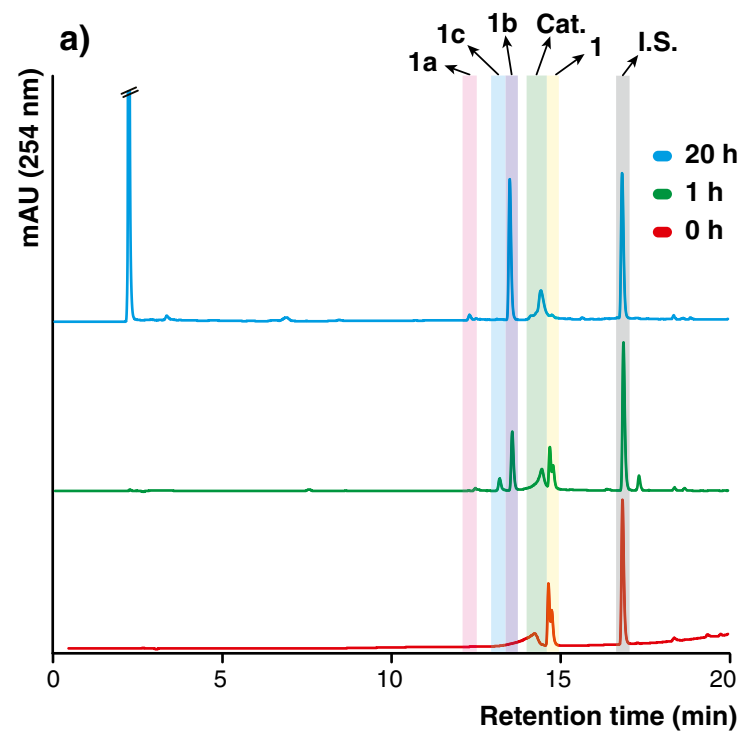

Fig. 4 HPLC chromatograms for reaction mixtures of (a) compound 1 at $0.27 \mathrm{MPa}(40 \mathrm{psi}) \mathrm{O}_{2}$ and (b) compound 2 at $1.24 \mathrm{MPa}(180 \mathrm{psi}) \mathrm{O}_{2}$ at different times. UV absorption is normalized. Preparations of samples
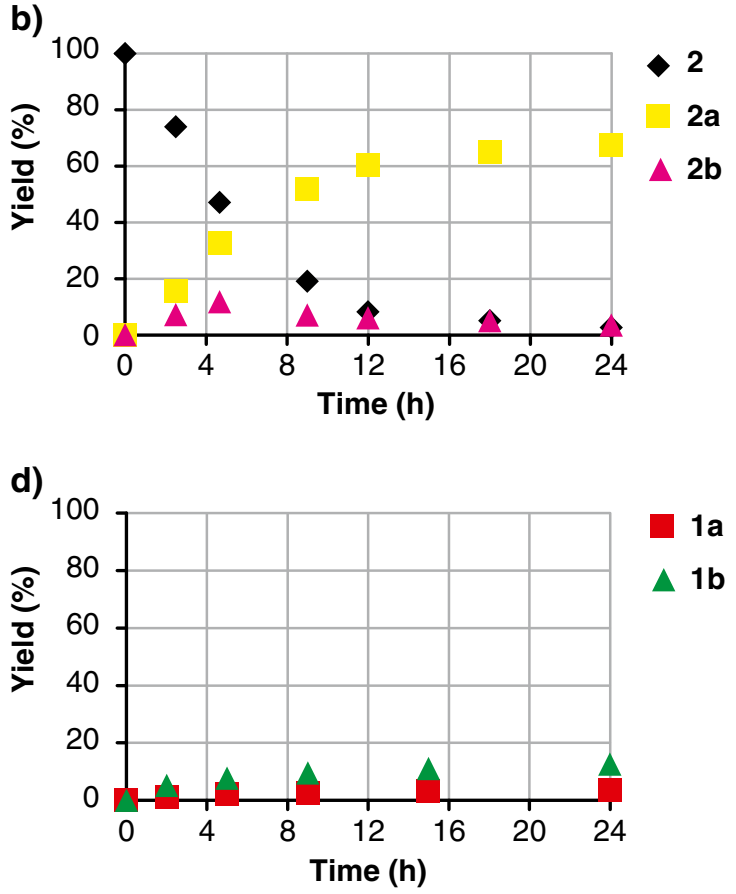

oligomer) at $0.27 \mathrm{MPa}(40 \mathrm{psi}) \mathrm{O}_{2}$ (data from Table $\left.\mathrm{S} 10\right)$, and (d) compound 4 (pine MW lignin) at $0.27 \mathrm{MPa}$ (40 psi) $\mathrm{O}_{2}$ (data from Table S11). Compound numbers are the same as in Fig. 2

and $4 \mathrm{~b}$ and Table S5). At $24 \mathrm{~h}$, nearly $3 \%$ of compound 2 remained. A continual increase in yield of $\mathbf{2 a}$ was observed with a higher final value compared to the same reaction at $0.27 \mathrm{MPa}$ (40 psi) $\mathrm{O}_{2}$, whereas veratraldehyde $\mathbf{2 b}$ reached a maximum and then decreased. Guaiacol 1c was not detected during this reaction. Figure $4 \mathrm{~b}$ shows HPLC chromatograms of products from this reaction. Similarly to in Fig. 4a, we

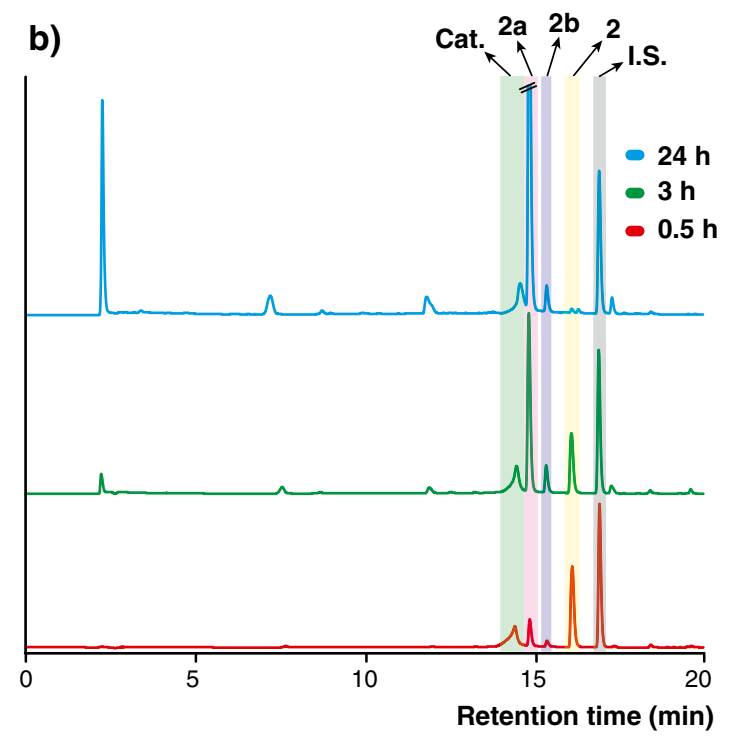

for both analyses are explained in the experimental section. Compound numbers are the same as in Fig. 2 
observed a sharp unresolved peak at lower retention time in the 24-h reaction product, again indicating the production of small hydrophilic molecules during the reaction. We also observed a few unknown and unidentified peaks in the middle of chromatogram. In separate experiments, we tested the possibility of improving the yields of the desired products by adding $5 \%$ (per mole) of butylated hydroxytoluene as a free radial scavenger to the reaction mixtures of compounds $\mathbf{1}$ and $\mathbf{2}$. We observed a slight increase in the yields of both acid and aldehyde products but degradation of the products was clearly not completely inhibited.

To analyze the stability of acids and aldehydes produced during these oxidation reactions, they were tested separately under catalytic alkaline oxidation at $1.24 \mathrm{MPa}(180 \mathrm{psi}) \mathrm{O}_{2}$ pressure. Vanillic acid 1a concentration decreased to $0 \%$ after $10 \mathrm{~h}$ (Fig. S1d and Table S6). Under the same conditions, vanillin $1 \mathrm{~b}$ concentration decreased to $13.5 \%$ at $24 \mathrm{~h}$ (Fig. S1e and Table S7) but the yield of vanillic acid, the expected product of vanillin oxidation, did not increase concomitantly; in fact, it increased to only $0.3 \%$ after $2 \mathrm{~h}$ and then dropped to $0 \%$. The result of veratric acid $\mathbf{2 a}$ oxidation (Fig. S1f and Table S8) revealed that the amount of the acid decreased to $84 \%$ after $24 \mathrm{~h}$, whereas under the same conditions, veratraldehyde $\mathbf{2 b}$ decreases to $60 \%$ (Fig. S1g and Table S9) and its expected oxidized product $\mathbf{2 a}$ increased gradually over the same time period. The faster degradation of acid 1a compared to acid $\mathbf{2 a}$ showed that the presence of the free hydroxyl group para to the side chain in A ring plays a crucial role in the vulnerability of $\mathbf{1 a}$ under oxidative conditions.

Further insight into the effects of etherified vs phenolic models was gained from polymeric models and lignins, the latter also allowing examination of reactions on the real polymer. Compound 3 (a $\beta$-ether oligomer with an average degree of polymerization of $\sim 10$ ) and pine MWL 4 (a pine isolated lignin or MWL) were analyzed following oxidation

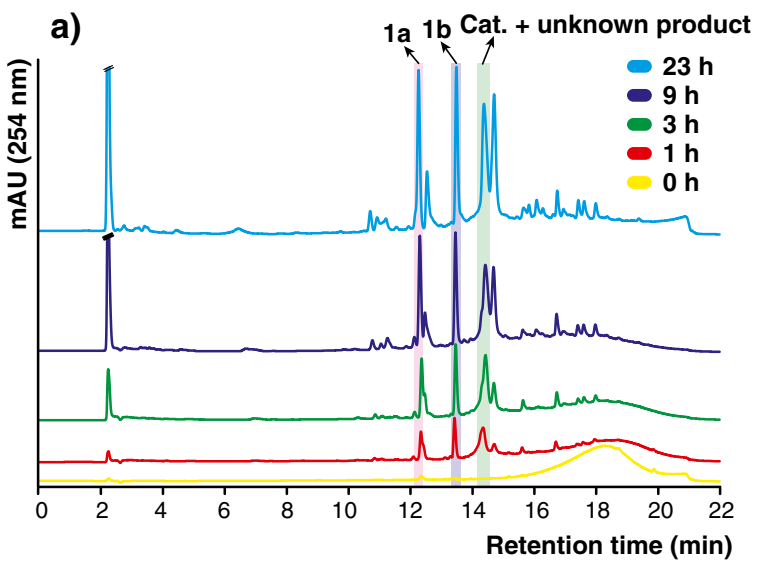

Fig. 5 (a) HPLC chromatograms of compound 4 (pine MWL) during catalytic oxidation at $0.27 \mathrm{MPa}(40 \mathrm{psi}) \mathrm{O}_{2}$ at different times. (b) GPC chromatograms showing molecular weight distribution changes of the same samples. Preparations of samples for both analyses are explained in at both $0.27 \mathrm{MPa}$ (40 psi) and 1.24 $\mathrm{MPa}$ (180 psi) $\mathrm{O}_{2}$ pressure while keeping other reaction conditions the same as for the model compound studies $(0.5 \mathrm{M} \mathrm{NaOH}, 5 \%$ catalyst per mole, and $80{ }^{\circ} \mathrm{C}$ ). The yields for vanillin $\mathbf{1 b}$ and vanillic acid 1a were measured. Under $0.27 \mathrm{MPa}$ (40 psi) $\mathrm{O}_{2}$ pressure, compound $\mathbf{3}$ yielded both $\mathbf{1 a}$ and $\mathbf{1 b}$. Their levels reached a maximum at $12 \mathrm{~h}$ and gradually decreased up to $24 \mathrm{~h}$ (Fig. 3c and Table S10). Pine, as a softwood, has a lignin composed primarily of guaiacyl-type phenylpropanoid units. Therefore, vanillic acid $\mathbf{1 a}$ and vanillin $\mathbf{1 b}$ are expected to be produced from its degradation. In the case of pine MWL 4, both $\mathbf{1 a}$ and $\mathbf{1 b}$ showed a constant increase in their yields up to $24 \mathrm{~h}$ (Fig. 3d and Table S11). Figure 5a shows the HPLC chromatograms of the whole catalytic alkaline oxidative reaction mixture of pine MWL 4. As expected, the reaction mixture became more complicated as the reaction proceeded. Similarly to in HPLC chromatograms for model compounds $\mathbf{1}$ and $\mathbf{2}$ in Fig. 4a, b, an unresolved and unidentified peak appeared at the beginning of the HPLC chromatogram. We are currently working to identify other products obtained from the pine MWL oxidation reaction. Increasing the $\mathrm{O}_{2}$ pressure to $1.24 \mathrm{MPa}$ (180 psi) had a negative impact on the yields of both vanillin and vanillic acid (data not shown).

To monitor pine MWL degradation and its possible structural changes, we used GPC and 2D NMR spectroscopy. GPC profiles of the whole reaction mixture from pine MWL 4 at different times (Fig. 5b) suggested the successful and anticipated massive depolymerization of lignin. It was observed that as the reaction proceeded, the size of the remaining lignin polymer in the reaction mixture became smaller, i.e., the area under the curve for the peak of the intact lignin at lower retention time decreased gradually and new unresolved peaks corresponding to the combination of smaller molecules continued to grow at higher retention times.

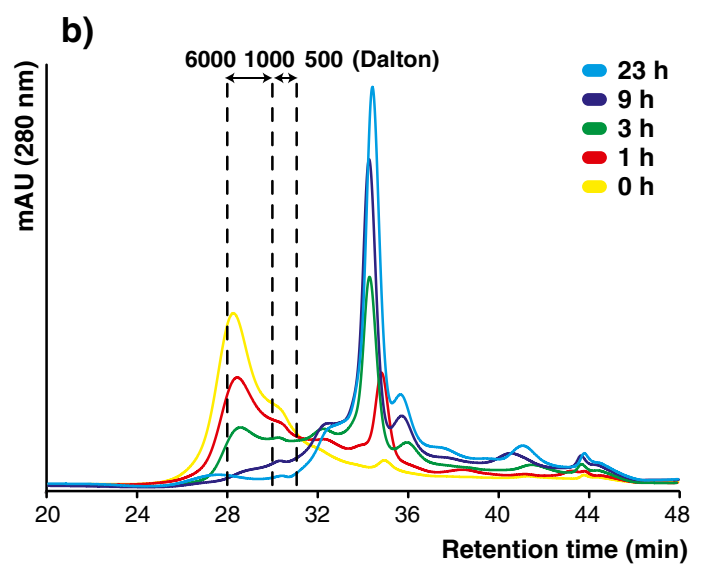

the experimental section. The 0 -h sample is the reaction mixture without catalyst. UV absorptions are not normalized. Compound numbers are the same as in Fig. 2 
We used 2D NMR spectroscopy to obtain further detailed structural characterization of the remaining lignin polymer in the reaction mixture at different times (Fig. 6; sample preparation is explained in the experimental section). Figure $6 \mathrm{a}, \mathrm{d}$ shows the common signals in the aliphatic and aromatic regions of the short-range ${ }^{13} \mathrm{C}-{ }^{1} \mathrm{H}$ correlation [heteronuclear single quantum coherence (HSQC) spectra] of intact pine MWL 4. After $1 \mathrm{~h}$ of oxidation, at $0.27 \mathrm{MPa}$ (40 psi) $\mathrm{O}_{2}$ pressure, the dibenzodioxocin $\mathbf{D}$ signals in the aliphatic region disappeared (Fig. 6b) suggesting its possible sensitivity under these conditions, whereas other signals consistent with $\beta$-ether $\mathbf{A}$, phenylcoumaran $\mathbf{B}$, and resinol $\mathbf{C}$ largely remained. Signals corresponding to oxidized (at the benzylic or $\alpha$-position) $\beta$-aryl ether units were not detected. After $1 \mathrm{~h}$ of oxidation (Fig. 6e), signals of guaiacyl $\mathbf{G}$ and $p$-hydroxyphenyl $\mathbf{H}$ units were present in the aromatic region, whereas the signals of oxidized guaiacyl units $\mathbf{G}^{\prime}$ were increased as expected. Also, signals for cinnamaldehyde end groups X3 were missing, whereas signals of benzaldehyde end units $\mathbf{X} \mathbf{1}$ were present and enhanced. The signals of $\beta$-ether, phenylcoumaran, and resinol units $\mathbf{A}-\mathbf{C}$ in the $2 \mathrm{D}$ NMR spectra after $10 \mathrm{~h}$ of oxidation (Fig. 6c) were present, whereas in the aromatic region (Fig. 6f), the signals for oxidized guaiacyl units $\mathbf{G}^{\prime}$ increased and $p$-hydroxyphenyl $\mathbf{H}$ units disappeared. a) $0 \mathrm{~h}$

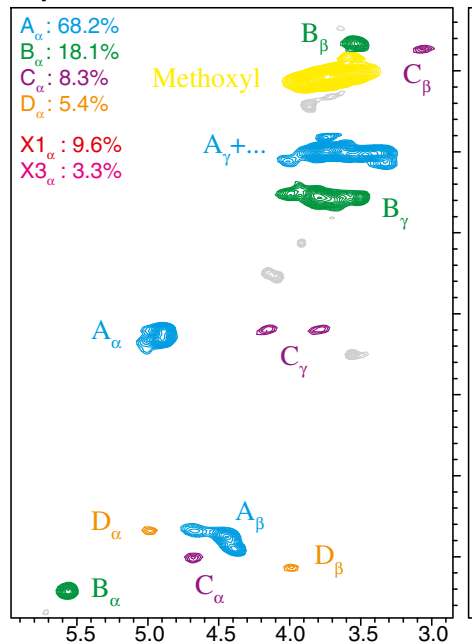

b) $\mathbf{1 h}$

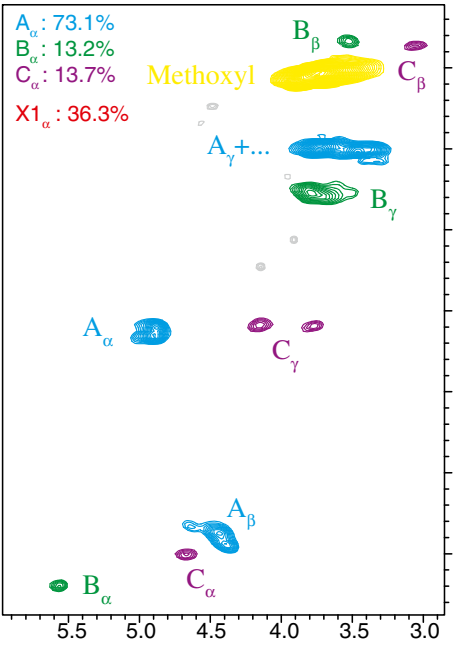

c) $10 \mathrm{~h}$

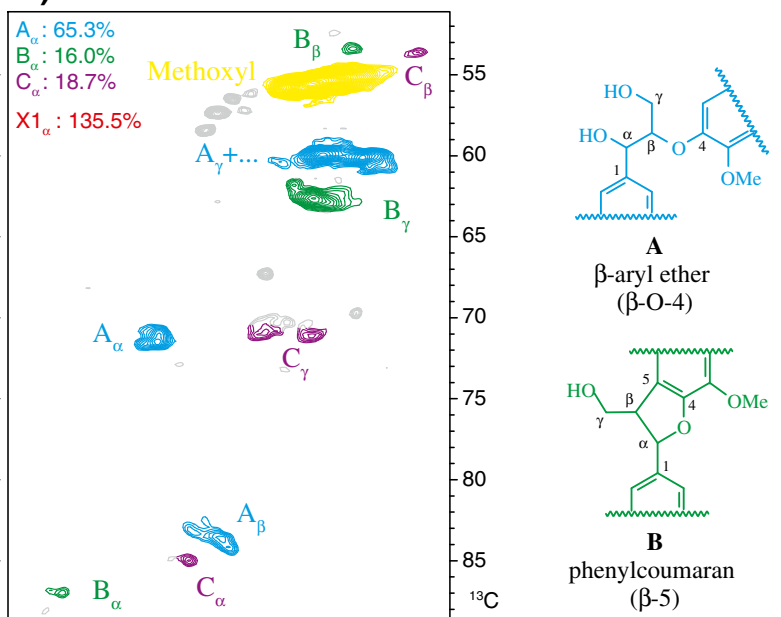

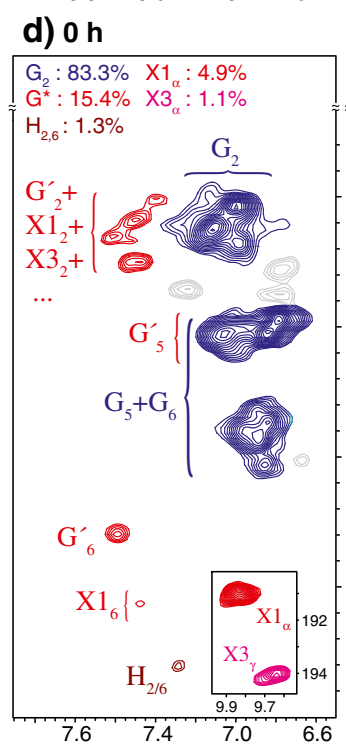

e) $1 \mathrm{~h}$ f) $10 \mathrm{~h}$

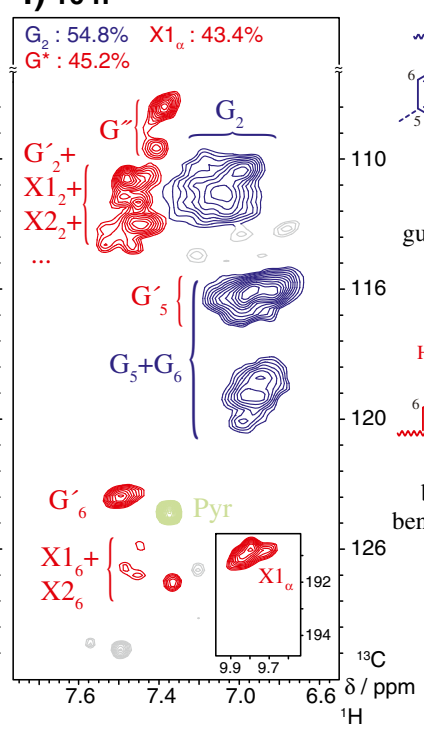

${ }_{1} \mathrm{H}$

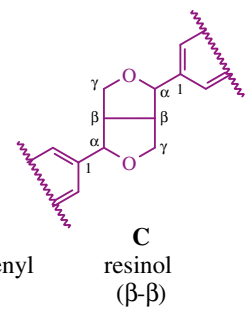

$(\beta-\beta)$
Fig. 6 2D HSQC NMR spectra including (relative) integrals from pine MWL 4 before $(0 \mathrm{~h})$ and after $(1$ and $10 \mathrm{~h})$ catalytic oxidation at $0.27 \mathrm{MPa}(40 \mathrm{psi}) \mathrm{O}_{2}$. (a-c) Aliphatic regions. (d-e) Aromatic regions of ${ }^{13} \mathrm{C}-{ }^{1} \mathrm{H}$ correlation spectra plus expanded area for aldehyde end groups. Note: in the aliphatic regions $(\mathbf{a}-\mathbf{c})$, the inter-unit linkage types
A-D add to $100 \%$, but the end units are expressed as a percentage of that total, i.e., they are, as conventional, not included in the total area calculation. Similarly, in the aromatic regions, $\mathbf{G}+\mathbf{G}^{\prime}+\mathbf{H}$ areas total $100 \%$, end groups $\mathbf{X} 1, \mathbf{X} \mathbf{2}$, and $\mathbf{X} \mathbf{3}$ are expressed as a percentage of this total 
We also observed some new signals in the NMR spectra corresponding to new structures that are under further study. $\beta$-Aryl ether, phenylcoumaran, and the biphenyl ether units (Fig. S2), all having an aldehyde or acid moiety as the end group, are tentatively assigned structures for the oxidized units because we could clearly observe their basic structures in the aliphatic region of the NMR; as other more reactive structures are broken and removed from the polymer, the less reactive units of the polymer remained in the reaction with their end groups being oxidized.

\section{Conclusions}

Catalytic alkaline oxidation of model compounds $\mathbf{1 - 3}$ and isolated lignin 4 under $\mathrm{O}_{2}$ pressure yielded the expected aromatic acids and aldehydes, but always in suboptimal yields. It was found that etherification of the phenolic hydroxyl group para to the side chain of ring A played an important role in the overall yields of acids and aldehydes, and in the yield distribution of aldehyde and acid products from the catalytic oxidation of compounds $\mathbf{1}$ and $\mathbf{2}$, suggesting dissimilar mechanisms were possibly involved in the catalytic alkaline oxidation reaction of these compounds.

Increased $\mathrm{O}_{2}$ pressure resulted in the production of many products and amplified the complexity of reaction mixtures from compounds $\mathbf{1}, \mathbf{3}$, and $\mathbf{4}$ but improved the product yields for catalytic oxidation of the etherified $\beta$-ether model compound $\mathbf{2}$. The chosen copper catalyst was found to improve the conversion speed of compounds $\mathbf{1 - 4}$ as well as to increase their monomer product yields.

The higher yields obtained for aldehyde $\mathbf{1 b}$ compared to acid $1 \mathrm{a}$ from the reaction of the $\beta$-ether oligomer (compound 3) were partially in agreement with the result of oxidation of compound 1, in which both compound 1 and end units of oligomer $\mathbf{3}$ had unprotected phenolic hydroxyl groups para to the ring A side chain. We were expecting to see similar yields from the oxidation reaction of oligomer $\mathbf{3}$ as it was an all $\beta$ ether "polymer," but this was not the case. Pine MWL 4 also produced only low yields of $\mathbf{1 a}$ and $\mathbf{1 b}$, suggesting the possible involvement of several side reactions that compete to produce other products or destroy the desired products. Of course, the other linkages in lignin could contribute to the low yields of $1 \mathbf{a}$ and $\mathbf{1 b}$, but the yields remain disappointing given the assumed (and calculated here, in Fig. 6a) $\beta$-ether content. We remain intrigued by the apparent reactivity of dibenzodioxocin structures $\mathbf{D}$ and of the other so-called condensed units (B and $\mathbf{C}$ ). The presence of unknown peaks in HPLC chromatograms of reaction mixtures from pine MWL 4 holds some promise for discovering new small molecules that could be produced from real-world lignin samples. However, it seems clear that obtaining near-theoretical yields of valuable products from the complex polymer remains a challenge.
Acknowledgments The authors gratefully acknowledge Ruili Gao, Dharshana Padmakshan, and Sally Ralph for providing model compounds for this study and Hoon Kim for his useful suggestions and assistance with NMR spectroscopy. We are grateful to Yuki Tobimatsu for his useful comments on GPC and NMR analyses. The authors gratefully acknowledge funding from the US Department of Energy's Great Lakes Bioenergy Research Center (DE-FC02-07ER64494).

Open Access This article is distributed under the terms of the Creative Commons Attribution License which permits any use, distribution, and reproduction in any medium, provided the original author(s) and the source are credited.

\section{References}

1. Cherubini F, Stromman AH (2011) Chemicals from lignocellulosic biomass: opportunities, perspectives, and potential of biorefinery systems. Biofuel Bioprod Bior 5(5):548-561

2. Tomani P, Axegard P, Berglin N, Lovell A, Nordgren D (2011) Integration of lignin removal into a kraft pulp mill and use of lignin as a biofuel. Cell Chem Technol 45(7-8):533-540

3. Alonso DM, Wettstein SG, Dumesic JA (2012) Bimetallic catalysts for upgrading of biomass to fuels and chemicals. Chem Soc Rev 41(24):8075-8098

4. Hocking MB (1997) Vanillin: synthetic flavoring from spent sulfite liquor. J Chem Educ 74(9):1055-1059

5. Ragauskas AJ, Williams CK, Davison BH, Britovsek G, Cairney J, Eckert CA, Frederick WJ, Hallett JP, Leak DJ, Liotta CL, Mielenz JR, Murphy R, Templer R, Tschaplinski T (2006) The path forward for biofuels and biomaterials. Science 311(5760):484-489. doi:10.1126/Science. 1114736

6. Baucher M, Monties B, Van Montagu M, Boerjan W (1998) Biosynthesis and genetic engineering of lignin. Crit Rev Plant Sci 17(2):125-197

7. Ralph J, Bunzel M, Marita JM, Hatfield RD, Lu F, Kim H, Schatz PF, Grabber JH, Steinhart H (2004) Peroxidase-dependent crosslinking reactions of $p$-hydroxycinnamates in plant cell walls. Phytochem Revs 3(1):79-96

8. Ralph J, Lundquist K, Brunow G, Lu F, Kim H, Schatz PF, Marita JM, Hatfield RD, Ralph SA, Christensen JH, Boerjan W (2004) Lignins: natural polymers from oxidative coupling of 4hydroxyphenylpropanoids. Phytochem Revs 3(1):29-60

9. Boerjan W, Ralph J, Baucher M (2003) Lignin biosynthesis. Annu Rev Plant Biol 54:519-549

10. Lu F, Ralph J (1997) Derivatization followed by reductive cleavage (DFRC method), a new method for lignin analysis: protocol for analysis of DFRC monomers. J Agr Food Chem 45(7):2590-2592

11. Zakzeski J, Bruijnincx PCA, Jongerius AL, Weckhuysen BM (2010) The catalytic valorization of lignin for the production of renewable chemicals. Chem Rev 110(6):3552-3599

12. Campbell AN, Stahl SS (2012) Overcoming the "oxidant problem": strategies to use $\mathrm{O}_{2}$ as the oxidant in organometallic C-H oxidation reactions catalyzed by Pd (and Cu). Accounts Chem Res 45(6):851-863

13. Das L, Kolar P, Sharma-Shivappa R (2012) Heterogeneous catalytic oxidation of lignin into value-added chemicals. Biofuels 3(2):155-166

14. Rahimi A, Azarpira A, Kim H, Ralph J, Stahl SS (2013) Chemoselective metal-free aerobic alcohol oxidation in lignin. J Am Chem Soc. doi:10.1021/ja401793n

15. Gaspar AR, Gamelas JAF, Evtuguin DV, Neto CP (2007) Alternatives for lignocellulosic pulp delignification using polyoxometalates and oxygen: a review. Green Chem 9(7):717-730

16. Germer EI (1995) Production of bleachable pulp through catalytic oxygen-alkaline delignification of high-yield mechanical pulp. TAPPI J 78(11):121-124 
17. Suchy M, Argyropoulos DS (2002) Catalysis and activation of oxygen and peroxide delignification of chemical pulps: a review. TAPPI J 1(2):9-9

18. Solomon EI, Sundaram UM, Machonkin TE (1996) Multicopper oxidases and oxygenases. Chem Rev 96(7):2563-2605

19. Wendlandt AE, Suess AM, Stahl SS (2011) Copper-catalyzed aerobic oxidative $\mathrm{C}-\mathrm{H}$ functionalizations: trends and mechanistic insights. Angew Chem Int Ed 50(47):11062-11087

20. Argyropoulos DS, Suchy M, Akim L (2004) Nitrogen-centered activators of peroxide-reinforced oxygen delignification. Ind Eng Chem Res 43(5):1200-1205

21. Korpi H, Lahtinen P, Sippola V, Krause O, Leskela M, Repo T (2004) An efficient method to investigate metal-ligand combinations for oxygen bleaching. Appl Catal Gen 268(1-2):199-206

22. Korpi H, Figiel PJ, Lankinen E, Ryan P, Leskela M, Repo T (2007) $\mathrm{On}$ in situ prepared $\mathrm{Cu}$-phenanthroline complexes in aqueous alkaline solutions and their use in the catalytic oxidation of veratryl alcohol. Eur J Inorg Chem 17:2465-2471

23. Asgari F, Argyropoulos DS (1998) Fundamentals of oxygen delignification. Part II. Functional group formation elimination in residual kraft lignin. Can J Chem 76(11):1606-1615

24. Gierer J (1982) The chemistry of delignification, a general concept, part 1. Holzforschung 36(1):43-51
25. Gierer J (1982) The chemistry of delignification, a general concept, part 2. Holzforschung 36(2):55-64

26. Kratzl K, Claus P, Lonsky W, Gratzl JS (1974) Model studies on reactions occurring in oxidations of lignin with molecular oxygen in alkaline media. Wood Sci Technol 8:35-49

27. Villar JC, Caperos A, GarciaOchoa F (1997) Oxidation of hardwood kraft-lignin to phenolic derivatives. Nitrobenzene and copper oxide as oxidants. J Wood Chem Technol 17(3):259285

28. Kishimoto T, Uraki Y, Ubukata M (2006) Chemical synthesis of $\beta$-O-4-type artificial lignin. Org Biomol Chem 4(7):13431347

29. Ralph J, Young RA (1981) Synthesis of the lignin model compounds threo-guaiacylglycerol- $\beta$-guaiacyl ether and threo-veratrylglycerol- $\beta$-guaiacyl ether. Holzforschung 35(1):39-41

30. Björkman A (1954) Isolation of lignin from finely divided wood with neutral solvents. Nature 174:1057-1058

31. Kim H, Ralph J (2010) Solution-state 2D NMR of ball-milled plant cell wall gels in DMSO- $\mathrm{d}_{6} /$ pyridine $\mathrm{d}_{5}$. Org Biomol Chem 8(3):576-591

32. Mansfield SD, Kim H, Lu F, Ralph J (2012) Whole plant cell wall characterization using solution-state 2D-NMR. Nat Protoc 7(9):1579-1589 